\title{
An Experimental Study on Pile Spacing Effects under Lateral Loading in Sand
}

\author{
Mahdy Khari, Khairul Anuar Kassim, and Azlan Adnan \\ Department of Geotechnics and Transportation, Faculty of Civil Engineering, Universiti Teknologi Malaysia, Skudai, \\ 81300 Johor Bahru, Malaysia
}

Correspondence should be addressed to Mahdy Khari; mehdikhari@gmail.com

Received 24 October 2013; Accepted 15 December 2013

Academic Editors: J.-Y. Lee and H.-H. Tsang

Copyright (c) 2013 Mahdy Khari et al. This is an open access article distributed under the Creative Commons Attribution License, which permits unrestricted use, distribution, and reproduction in any medium, provided the original work is properly cited.

\begin{abstract}
Grouped and single pile behavior differs owing to the impacts of the pile-to-pile interaction. Ultimate lateral resistance and lateral subgrade modulus within a pile group are known as the key parameters in the soil-pile interaction phenomenon. In this study, a series of experimental investigation was carried out on single and group pile subjected to monotonic lateral loadings. Experimental investigations were conducted on twelve model pile groups of configurations $1 \times 2,1 \times 3,2 \times 2,3 \times 3$, and $3 \times 2$ for embedded length-to-diameter ratio $l / d=32$ into loose and dense sand, spacing from 3 to 6 pile diameter, in parallel and series arrangement. The tests were performed in dry sand from Johor Bahru, Malaysia. To reconstruct the sand samples, the new designed apparatus, Mobile Pluviator, was adopted. The ultimate lateral load is increased 53\% in increasing of $s / d$ from 3 to 6 owing to effects of sand relative density. An increasing of the number of piles in-group decreases the group efficiency owing to the increasing of overlapped stress zones and active wedges. A ratio of $s / d$ more than $6 d$ is large enough to eliminate the pile-to-pile interaction and the group effects. It may be more in the loose sand.
\end{abstract}

\section{Introduction}

Superstructures are supported by pile foundations so that it had its origin in prehistoric time. These foundations may be subjected to significant horizontal loads such as dynamic and static loadings. Two criteria shall be controlled to satisfy of functioning such structures: (1) their deflection which must be within the permissible limit and (2) safety of pile against ultimate failure. The behavior of the pile group and the single pile is usually different owing to the impacts of the pile-to-pile interaction (so called shadowing effects). In addition, soil-pile coupling behavior is important when the load transfer occurs [1]. Evaluation of the pile group behavior and the soil-pile interaction has developed by several investigators in experimental and analytical modeling [2-4]. Existing methods of the analytical modeling can be classified into numerical approaches, Beam on Nonlinear Winkler Foundation method (BNWF), and simplified formulations [5]. Although most of these approaches are attended on evaluation of the stiffness of the soil-pile system, they are less focused on the bending moment and the lateral resistance of the group.

It is worth noting that the estimations of ultimate lateral resistance and lateral subgrade modulus within a pile group are known as they are the key parameters in the soil-pile interaction phenomenon. Several theoretical methods have been developed to determine these parameters in cohesionless soils. However, the predictions of these approaches are often different. On the other hand, the laterally loaded pile group behavior has received a little attention. Moreover, the experimental data on the determination of active pile length and bending moment are inadequate. Therefore, it is necessary to increase the experimental data for the response of the pile group under lateral loads.

This paper presents the results of a series of experimental investigations carried out on single and grouped piles subjected to the monotonic lateral loads in Johor Bahru sand in the southern portion of Malaysia. Emphasis was focused on group efficiency and load-deflection behavior owing to the influence of relative density, size group, and pile spacing. 


\section{Brief Review}

As mentioned in the foregoing section, the shadowing phenomenon affects the pile behavior within the group under the lateral loading [6]. Although many researchers have studied the ultimate lateral resistance and deflection of the pile group to a lateral loading, they are complex due to the interaction between the surrounding soil and the pile [7].

In 1962, Prakash carried out the pile group behavior under the lateral loading using aluminum pipes (od $=12.7 \mathrm{~mm}$; $d=$ pile diameter) in the medium sand. Based on these tests, it was stated that the sum of pile capacities was more than that within the group when the spacing center-to-center of piles was less than $3 d$ and $8 d$ in the direction perpendicular and the direction to load, respectively. Meyerhof et al. [8] conducted tests in homogeneous sand on pile groups and rigid single pile under central inclined loads. The bored piles were tested by Franke [9] in the experimental tests. The results showed that the displacement of a group was more than a single pile in the same loading when the piles spacing was less than $6 d$. Patra and Pise [10] studied the ultimate lateral resistance on six types of configurations of pile group with different embedment length-to-diameter ratios equal to 12 and 38 . Their results were compared with the results of analytical methods. Based on their report, it can be stated that the isolation spacing is six times of pile diameter for $l / d=12$.

Kim and his workers [11] investigated lateral load tests on aluminum single pile (driven and drilled) in dry sand. In addition, they considered the head conditions of the piles. The lateral loads of the preinstalled were less than those of the driven piles.

Zhang et al. [12] proposed the ultimate lateral resistance in cohesionless soils. They collected the experimental data done by other researchers on rigid piles and a simple method was developed by them to predict the ultimate lateral resistance (involving of side shear resistance and frontal soil resistance) to piles considering the shape factor. Another method was developed by Prakash and Kumar [13]. In this method, loaddisplacement relationship was predicted by means of considering soil nonlinearity using subgrade reaction. Erdal and Laman [14] purposed the behavior of short pile subjected to lateral loads in a two-layer sand deposit. The pile modeled had an embedded length-to-diameter ratio of 4 and fabricated from steel for all the tests. Based on their results, it can be stated that the lateral load capacity of short rigid piles in the dense sand was 5 times that in loose sand.

\section{Experimental Setup}

The schematic diagram of the test setup is shown in Figure 1. The model tests were performed in a rectangular soil tank with dimensions of $900 \mathrm{~mm}$ in length, $700 \mathrm{~mm}$ in width, and $65 \mathrm{~mm}$ in height. To consider the boundary conditions, the size of the soil tank was extended up to $8-12 d$ ( $d=$ pile diameter) and 3-4d in the direction and perpendicular to the lateral loading, respectively [15]. In additional, to minimize the influence of box boundaries, the soil thickness was kept below the pile tip at least $6 d$.

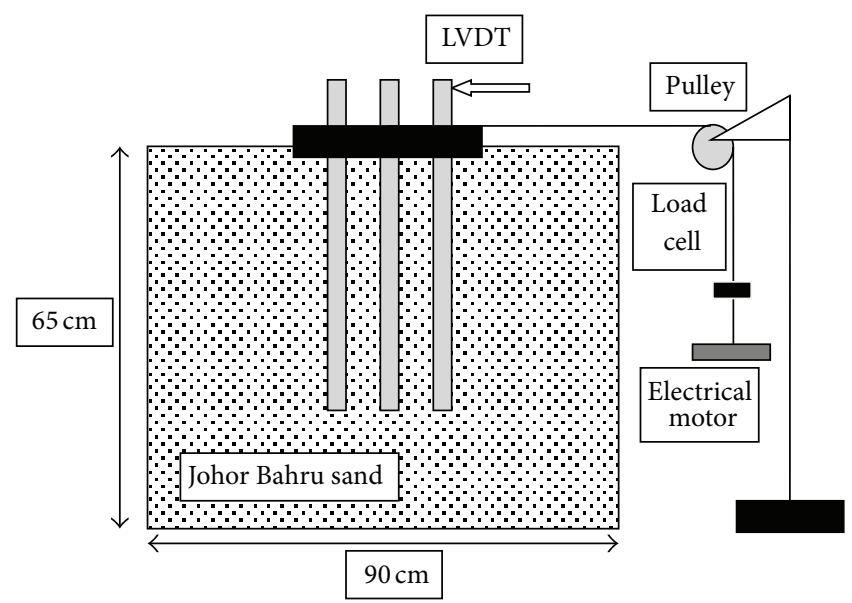

FIGURE 1: Side view of experimental setup.

The model piles with an open end and hollow circular section were fabricated from aluminum alloy tubes $\left(E_{p}=\right.$ $69.8 \mathrm{GPa}$ ) of $15.88 \mathrm{~mm}$ out diameter, $1 \mathrm{~mm}$ wall thickness and an embedded depth of $500 \mathrm{~mm}$. It is worth noting that, for the pile properties and the selected soil, pile behaves as flexible pile.

Three plates made of steel were used as pile cap for different spacing. To satisfy fixed head conditions, the piles were passed through exiting holes in the cap and then screwed to angle profiles (length $=50 \mathrm{~mm}$ ) welded on these holes. Lateral loads were applied to the model piles using a $650 \mathrm{~N}$ capacity electric motor through a pulley supported by a loading platform with flexible wire attached to the cap.

The horizontal deflection of the pile group was measured by means of two Linear Variable Differential Transducers (LVDT) to the angle profiles of the two corner piles. The rotation of cap was determined from axial displacement measured by other two LVDTs fixed on front and behind of the cap in load direction. A load cell was placed between the flexible wire and electric motor to monitor the total loads applied to the pile cap.

\section{Soil Properties and Sample Preparation}

The tests were conducted in dried sand (in the laboratory temperature) from Johor Bahru sand. The sampled sand was classified as SP, according to the Unified Soil Classification System (USCS). The medium diameter $\left(D_{50}\right)$ and uniformity coefficient $\left(C_{u}\right)$ of sand were 0.532 and $0.17 \mathrm{~mm}$, respectively, and particle sizes in a range of $0.075-0.97 \mathrm{~mm}$ with the gradation are shown in Figure 2. Based on a standard density test, minimum and maximum unit weights of sand were $13.74 \mathrm{kN} / \mathrm{m}^{3}$ and $16.38 \mathrm{kN} / \mathrm{m}^{3}$.

To reconstruct the sand samples, several methods have been developed by investigators such as vibration, tamping, and pluviation [16]. The prepared samples using the pluviation and tamping technique often result in a specimen of homogenous and nonuniform density, respectively. Based on this defect, the newly designed Mobile Pluviator was utilized in this research to reconstruct the dry sandy soil samples 


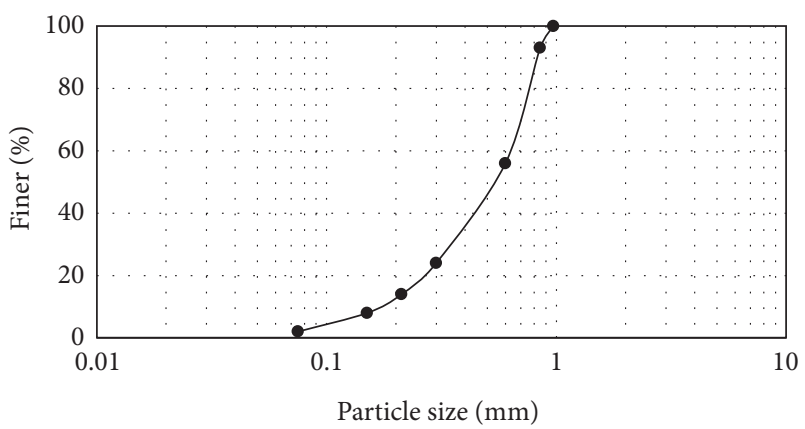

Figure 2: Gradation curve of the Johor Bahru sand.

using the dry pluviation method. The newly Mobile Pluviator developed was consisting mainly of a soil bin (hopper), the diffuser system (the three sieves), sand collector, and a fixing device to set up these components so as the whole of the system was carried by a moveable steel frame. The interchangeable circular wood plates (shutter plates) were installed in the bottom of the sand hopper. The four patterns of the shutter plates were formed in a manner of the distribution differently of the holes for the sake of control of the rate of the soil discharge. While the apparatus was movable, the different factors were examined to obtain a wide range of the relative density. The falling height and the rate of pouring had the opposite effects on the relative density. Based on the results obtained, the two patterns selected consisted of 11 holes $($ diameter $=18 \mathrm{~mm})$ and 16 holes $($ diameter $=10 \mathrm{~mm})$ distributed evenly in the shutter to achieve the dense and the loose sand samples with relative density of $75 \%$ and $30 \%$, respectively. The falling height was kept constant a $700 \mathrm{~mm}$ from the surface of the model ground which was more than the critical height so that to obtain terminal velocity. The raining was stopped when the sand rained in the soil tank was $30 \mathrm{~mm}$ thicker than required and then the extra soils were removed.

\section{Test Procedure}

Different configurations of pile groups in different spacing are shown in Figure 3. The center-to-center spacings of the piles were $6 d$ and $3 d$, and embedment ratio of 32 was tested. Spacing ratio (SR $=S_{2} / S_{1}$, where $S_{2}$ and $S_{1}$ are the piles spacing in perpendicular and direction of lateral load applied, resp.) was equal to $0.5,1$ and 2 . In addition, several tests were conducted on single pile. The piles (fixed with the cap) were first located in the center of soil tank and then were kept in a vertical statue using a supporting frame. After placing the model pile, the Mobile Pluviator apparatus was installed over soil box. To monitor uniformity and the relative density during the samples preparation, three small boxes cylinder shaped of $455 \mathrm{~cm}^{3}$ were placed on the surface of sample prior to sand spreading. The surface of the model ground was leveled when the required height was achieved. At least 24 hours elapsed before applying any test on the pile group. The data measured from LVDTs and load cell were stored on a computer data acquisition system.

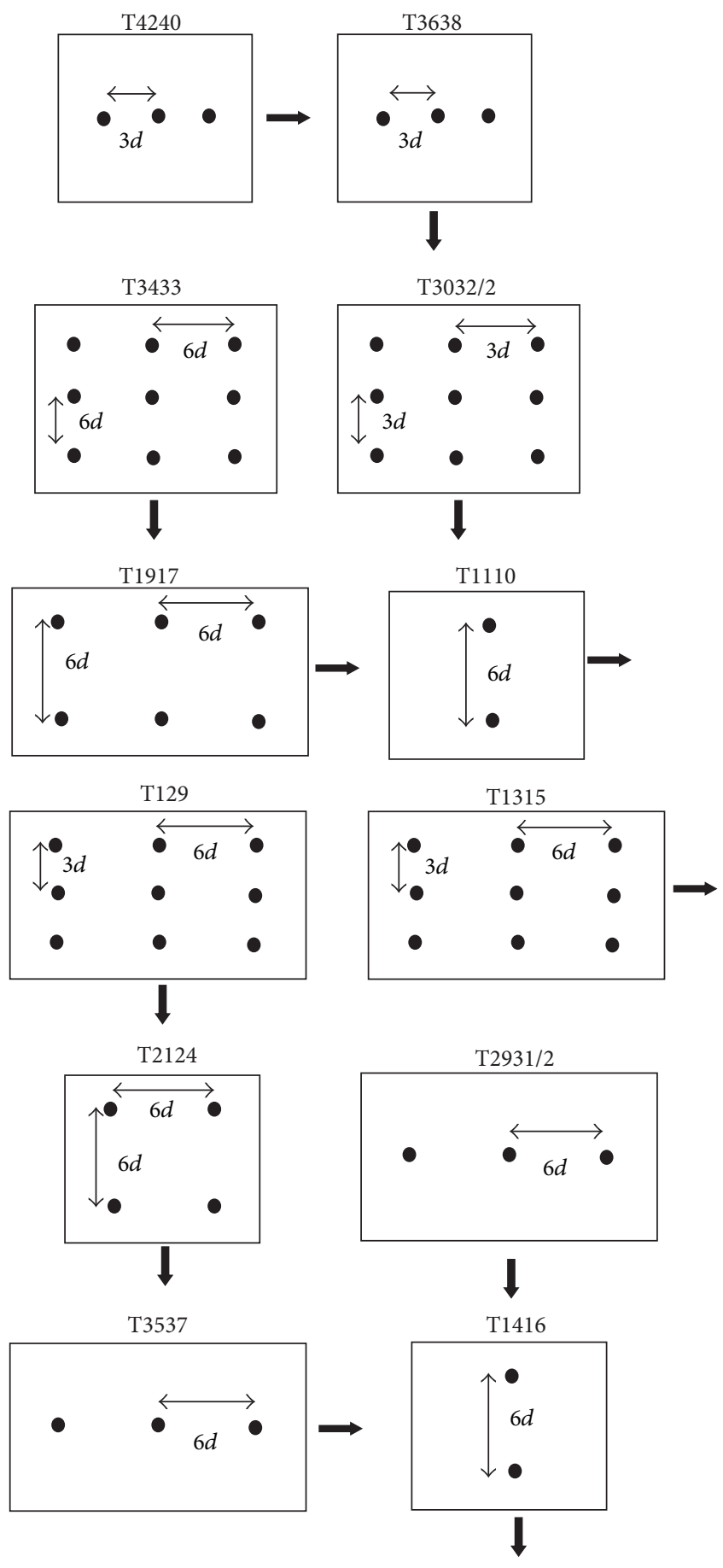

FIGURE 3: Pile group configurations and pile spacing ratio ( $\uparrow$ is the lateral loading direction).

\section{Experimental Results and Discussion}

A series of 45 tests were performed on piles to investigate the influences of soil density and different pile configurations on the ultimate lateral resistance and pile group efficiency. The pile groups were loaded in an incremental manner. The nonlinear load versus lateral displacement and vertical settlement of the pile cap could be adequately defined. 


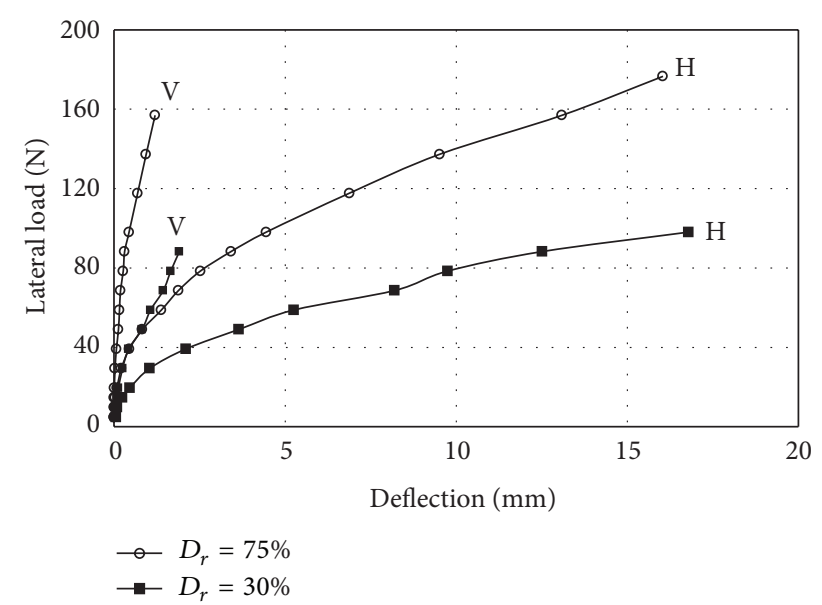

FIgURE 4: Lateral load versus deflection diagram for single pile ( $\mathrm{H}=$ horizontal; $\mathrm{V}=$ vertical $)$.

The soil density effects on single pile against the average pile deflection are presented in Figure 4. From the figure it is seen that the load-deflection curves were nonlinear and a similar trend was observed in loose and dense conditions. Vertical displacements were negligible compared to horizontal deflections and it is in agreement with previous studies which stated that soil-pile interaction could be determined separately under lateral and vertical loads. The differences of the lateral deflection increased when the relative density increased from $30 \%$ to $75 \%$ under the same moment of load. Therefore, a higher relative density will provide a stiffer resistance for pile subjected to lateral loading. This is owing to the increasing of shear strength of sand as it becomes denser. In other words, pile behavior subjected to lateral loads depends on the interaction between the surrounding soil and pile material.

The influence of the piles' spacing on the lateral deflection and group behavior for the $3 \times 3$ pile group with a square arrangement are shown in Figures 5 and 6. For a particular value of lateral movement, the magnitude of lateral load decreased when the piles' spacing decreased in dense and loose sand. At the deflection of $0.1 d$, the lateral load of the pile group was about 2.90 times higher than that of the single pile in the case of 6-diameter, 1.85 times higher for $s / d=3$.

Figure 7 illustrates the influences of piles number ingroup on the value of the deflection against the lateral load. Compared to Figure 5, it is observed that when the piles' spacing was the same, the magnitude of lateral load however was higher for larger groups. comparing between Figures 6 and 7 , the load-deflection curves were almost similar. This may be due to the area of ground pressure in front of the pile group. This indicates that, although the number of piles contributes to the value of lateral resistance, the piles' spacing is the most significant factor.

Figures 8 and 9 illustrate the behavior of the loaddeflection of pile group in both series and parallel arrangements were investigated for a three-piles group in the spacing of the center-to-center piles of $3 d$ and $6 d$. From these Figures,

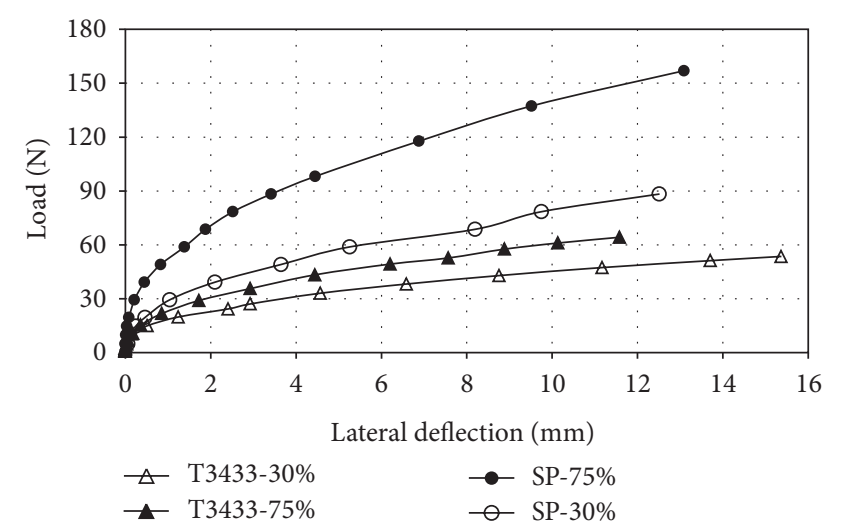

Figure 5: Lateral load versus lateral deflection $(3 \times 3$ pile group; $s / d=6)$.

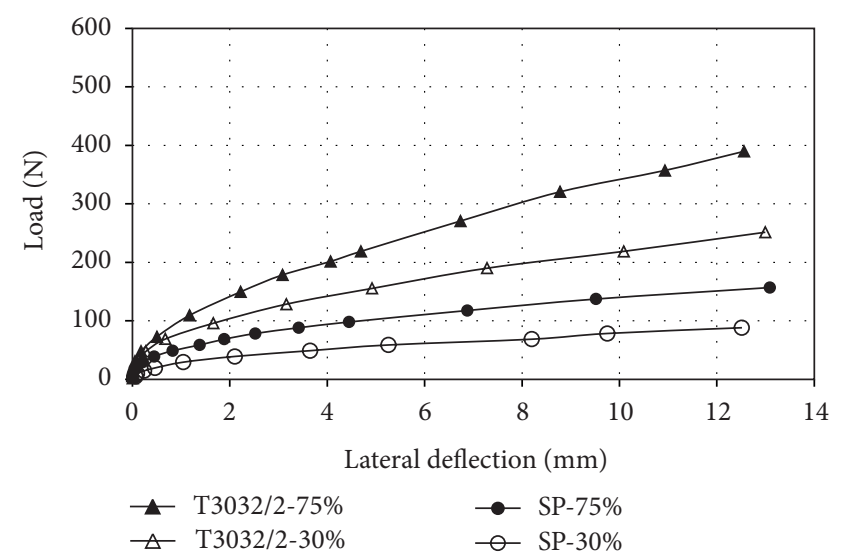

FIGURE 6: Lateral load versus lateral deflection $(3 \times 3$ pile group; $s / d=3)$.

it can be seen that the piles' deflection in parallel arrangement was less than that in series arrangement under a given lateral load. The higher lateral load capacities in parallel arrangement was governed by the increased passive pressure zone existed in front of the pile group. A similar comparison was made for different relative densities of soil, which shows that a similar phenomenon occurred.

It should be noted as shown in Figures 8 and 9 that the effect of the stressed zone around piles for series arrayed piles was less than that for parallel arrangement. However, both stress zones may be dependent on the dimensions and the elastic modulus of the piles. Since the piles were assumed flexible, the failure of the surrounding soil will be earlier as compared to the piles.

\section{Ultimate Lateral Resistance}

The ultimate lateral resistance in the different arrangements of pile groups was estimated by the load-deflection curves. The soil resistance to piles under lateral load may be involving of the side friction and the frontal normal reaction [17]. However, these two reactions are dependent on shape factor taking in account nonuniform distribution of earth pressure 


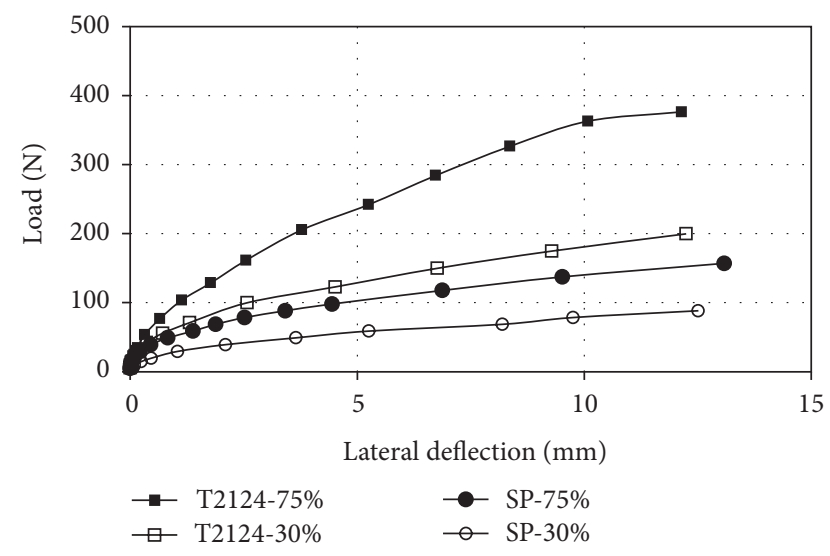

FIgURE 7: Lateral load versus lateral deflection $(2 \times 2$ pile group; $s / d=6)$.

in front of pile and lateral shear drag. There are several methods to estimate the ultimate lateral resistance such as double tangent and log-log method. In this study, the ultimate lateral resistance was taken as the load corresponding to the reference deflection of $0.2 d$ on the load-deflection curves [18]. The results obtained exhibit that the increasing rate of deflection was reached at about $0.2-0.35 d$. Figure 10 shows the influence of the piles' spacing versus ultimate lateral resistance. The ultimate lateral load was constant with an increase from $3 d$ to $6 d$ in parallel arrangement of piles for group $1 \times 3$ in dense sand. However, the increasing can be observed more than that in series arrangement of piles. From the figure, It is worth noting that the relative density affects ultimate resistance because of passive pressure zone existed in front of the pile group. The piles' spacing in the perpendicular direction to load applied may affect the ultimate resistance load due to the stressed zone in front of the pile group. The ultimate lateral resistance of single piles was 84.013 and $44.5(\mathrm{~N})$ for loose and dense sand, respectively. With note to the ultimate load in group and single pile, the effects of the shadowing phenomenon can be observed so as the increasing of the pile spacing causes the same in group and individual. The ultimate lateral load in single pile was about $25 \%$ of the ultimate load for $3 \times 3$ pile group (T3433) while this percentage for $\mathrm{T} 3032 / 3$ was about $47 \%$. In fact, with increasing of the pile spacing from $3 d$ to $6 d$, the value of ultimate lateral load about $0.53 \%$ is increased.

\section{Group Efficiency}

Variation of the pile group resistance at a given deflection is expressed by group efficiency $(\eta)$ and is calculated as follows:

$$
\eta=\frac{Q_{\mathrm{LG}}}{n_{1} n_{2} \mathrm{Q}_{\mathrm{LS}}},
$$

where $Q_{L G}$ and $Q_{L S}$ are ultimate lateral capacity of pile group and single pile, respectively. $n_{1}$ is number of rows in a pile group; $n_{2}$ is number of columns in a pile group.

Wakai et al. [19] performed the laboratory tests on a $3 \times$ 3 pile group with free and fixed head conditions $(s=2.5 d)$.
The group efficiency was estimated $0.45-0.70$ at the deflection of $0.1 d$. However, the group efficiency obtained based on the ultimate lateral loading can be higher than that at a given deflection. Kim and Yoon [20] carried out the static loading tests on the different pile arrangements. They calculated the group efficiency when the deflection was reached $0.1 d$. In $3 \times$ 3 pile group, the coefficient was $0.4-0.7$ and $0.5-1.04$ for the medium dense and the medium sand, respectively.

Gandhi and Selvam [21] stated that, at the $10 \mathrm{~mm}$ displacement, pile behavior is crossed through elastic to plastic range. They considered this deflection to estimate the group efficiency. Based on their results, the efficiency increases with an increase in the $s / d$ ratio and this raising can be due to the increasing of the overlapping zones.

Patra and Pise [10] and Oteo [22] carried out a series of tests on different configurations of pile groups under the lateral loading. Oteo reported model tests on $3 \times 3$ piles group in medium send. Patra and Pise reported the groups' efficiencies for $2 \times 1,3 \times 1,2 \times 2$, and $3 \times 2$ for pile spacing from $3 d$ to $6 d$. As Figure 11 shows, the experimental results in this study for $3 \times 1$ pile group at $3 d$ and $6 d$ were about $50 \%$ less than those the reported by Patra and Pise. However, the measured group efficiencies were in good agreement with those of Oteo.

The variation group efficiency against of spacing ratio (SR $=S_{2} / S_{1}$, where $S_{2}$ and $S_{1}$ are the piles spacing in perpendicular and direction of lateral load applied, resp.) is presented in Figure 12 for $3 \times 3$ piles group in the different relative densities. It can be stated that the group efficiency was decreased about 0.35 and 0.25 in the loose and the dense sand where $S_{1}=S_{2}$. However, this value was increased for $S_{2} \neq S_{1}$. The group efficiencies were the same for the $S_{2} / S_{1}$ ratio almost equal to 0.5 and 2 . The group efficiency was higher in relative density by $30 \%$. For a $3 \times 3$ piles group, the observed efficiency was about $0.23-0.28 \%$ and $0.32-.41 \%$ for $D_{r}=75 \%$ and $D_{r}=30 \%$, respectively. As Figure 13 shows, the group efficiency was decreased with an increase in the number of piles arrayed in group. This decreasing with an increase of the number of piles in pile spacing of $6 d$ and $3 d$ was almost the same. However, the group efficiency was about $0.68-0.84 \%$ for $s=6 d$ and $0.35-0.68 \%$ for $s=3 d$.

Pise and Patra [10] carried out a series of the tests for $3 \times 3,3 \times 1,2 \times 2$, and $2 \times 1$ piles groups. The efficiencies obtained were $0.752-1.0$ and $0.9-1.2$ for the $3 \times 2$ and the $3 \times 3$ piles group, respectively. These efficiencies were higher (about $42 \%-78 \%$ ) than those obtained in this study for $s / d=3$ and 6.

\section{Conclusions}

The behavior of single pile and grouped is believed to be understood, especially for soils where the subgrade modulus is independent of time. Based on this demand, a series of tests were carried out on pile group under lateral static loading in sandy soils. A new method of the reconstruction of sand samples was developed for large area of samples. Based on the results of present experiment, the following conclusions are drawn. 


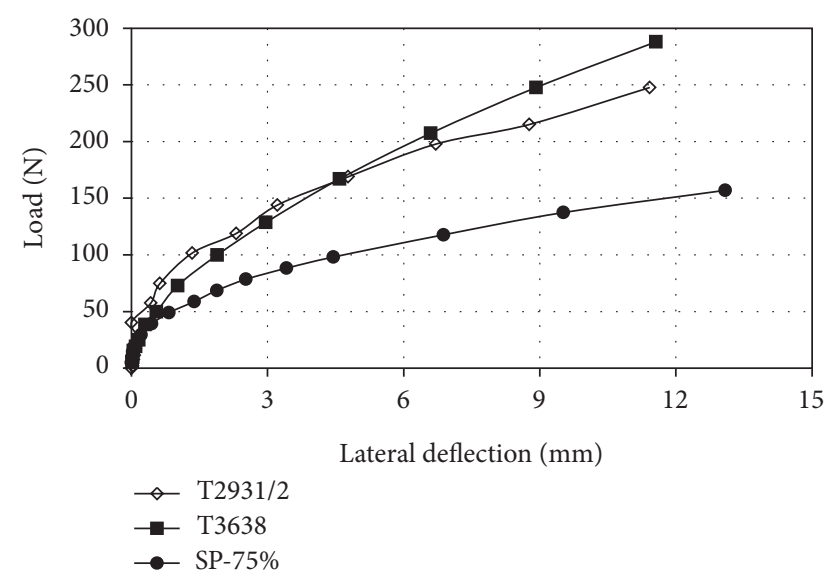

(a)

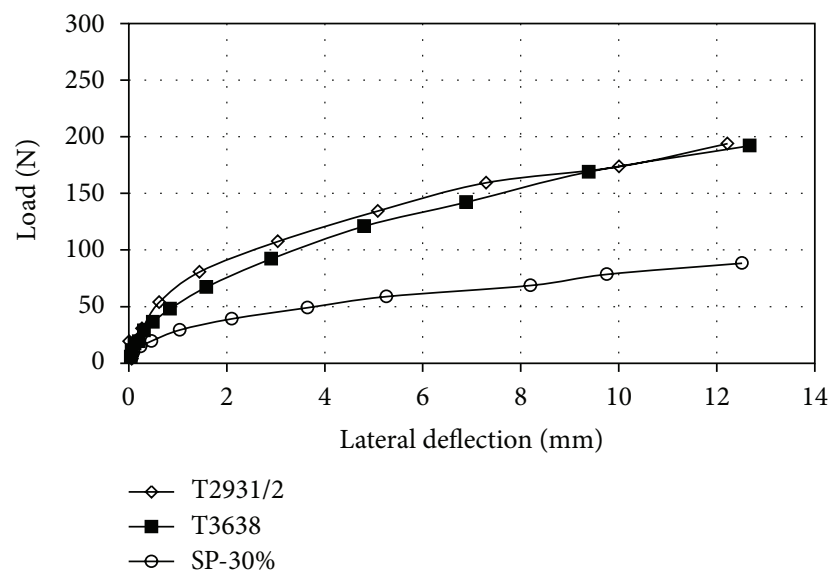

(b)

FIGURE 8: Lateral load versus lateral deflection for three-pile group in series layout; (a) $D_{r}=75 \%$ and (b) $D_{r}=30 \%$.

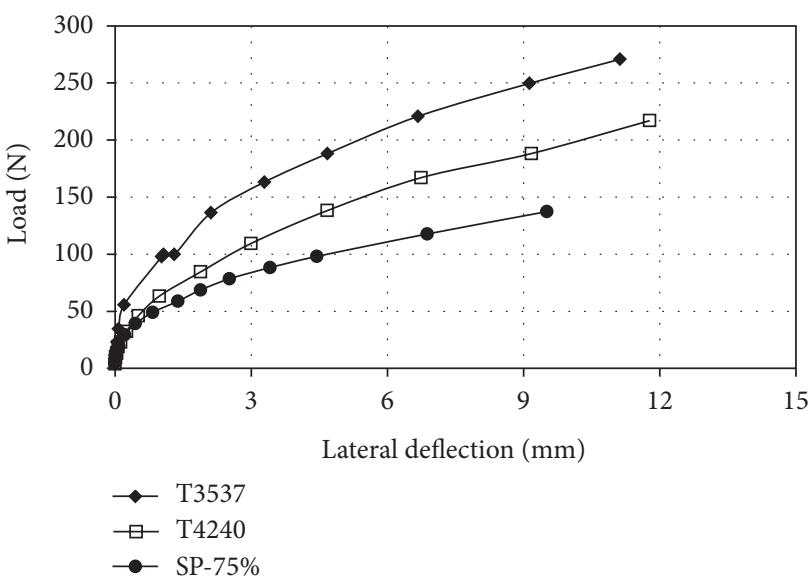

(a)

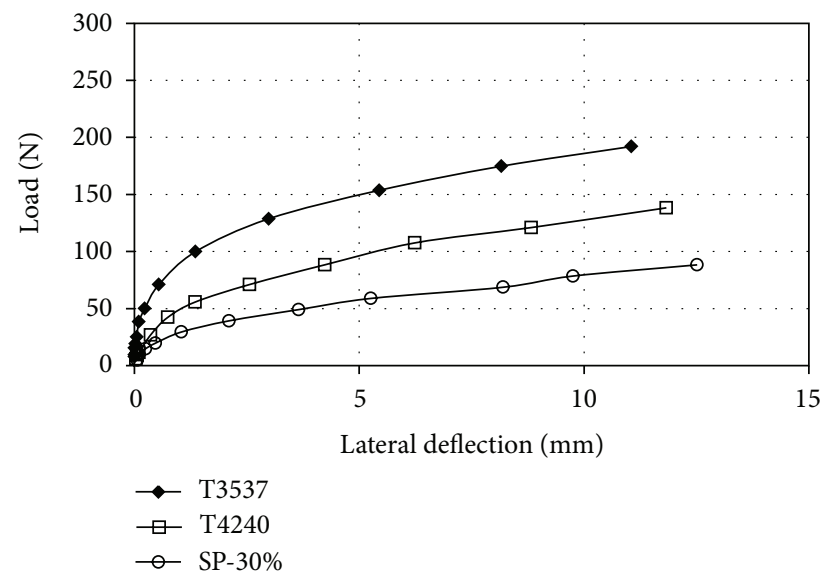

(b)

FIgURE 9: Lateral load versus lateral deflection for three-pile group in Parallel layout; (a) $D_{r}=75 \%$ and (b) $D_{r}=30 \%$.

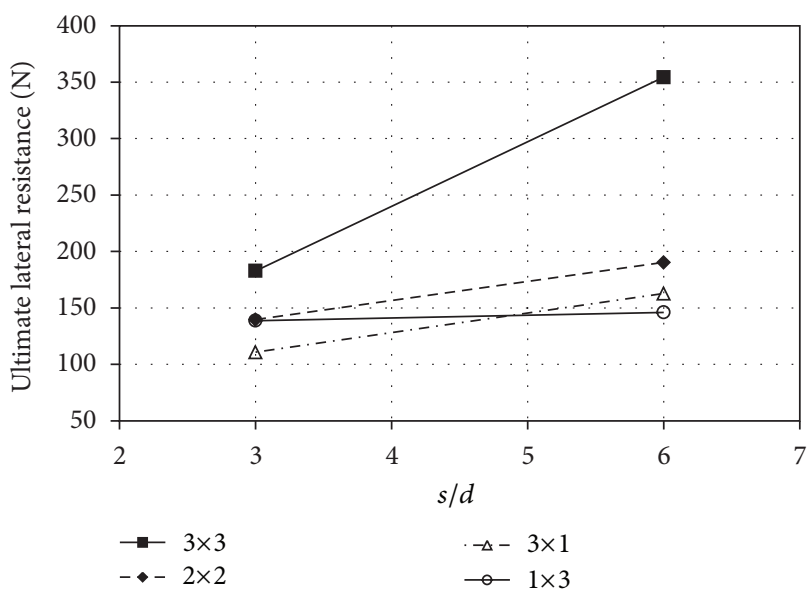

(a)

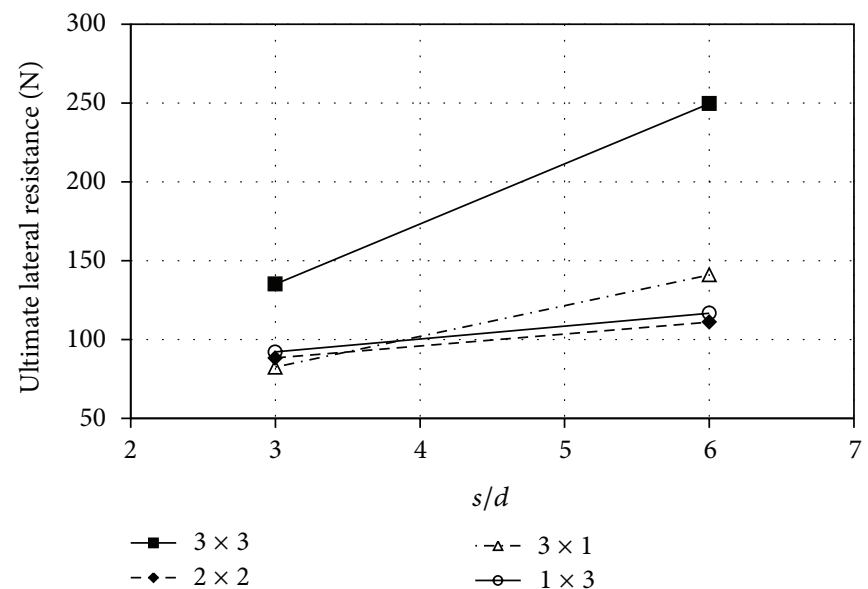

(b)

Figure 10: Ultimate lateral load versus pile spacing; (a) $D_{r}=75 \%$ and (b) $D_{r}=30 \%$. 


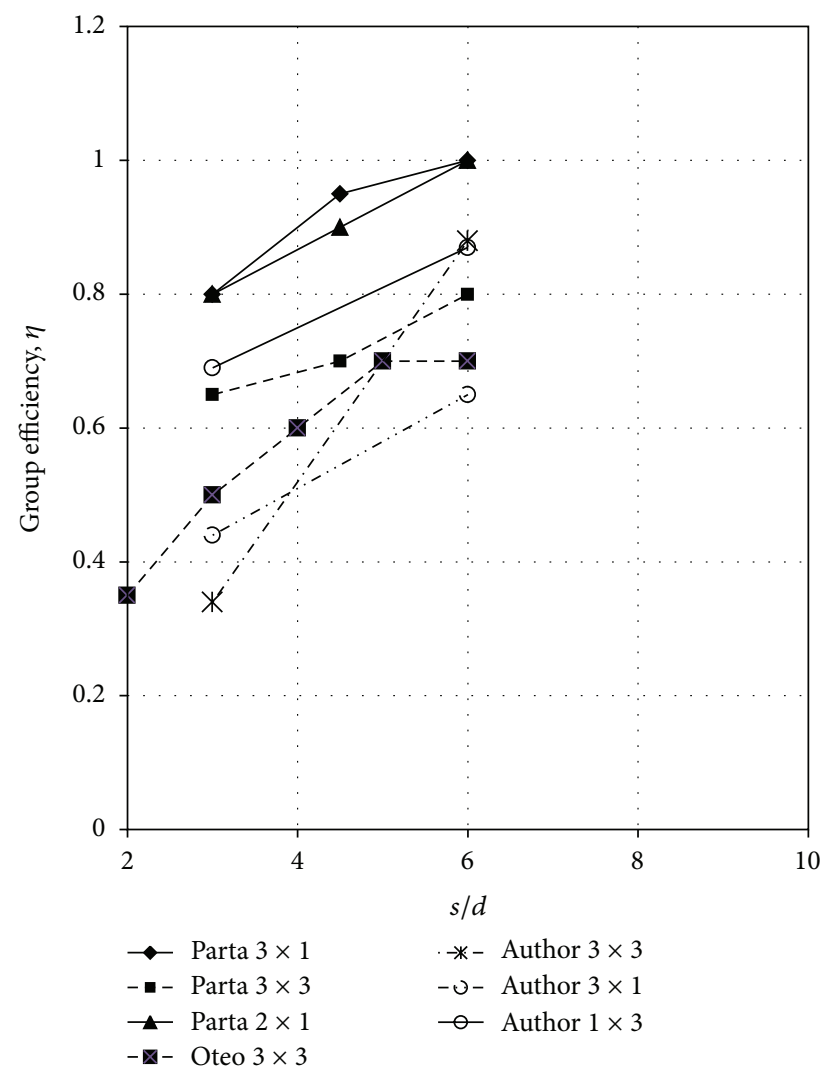

FIGURE 11: Comparison of group efficiencies.

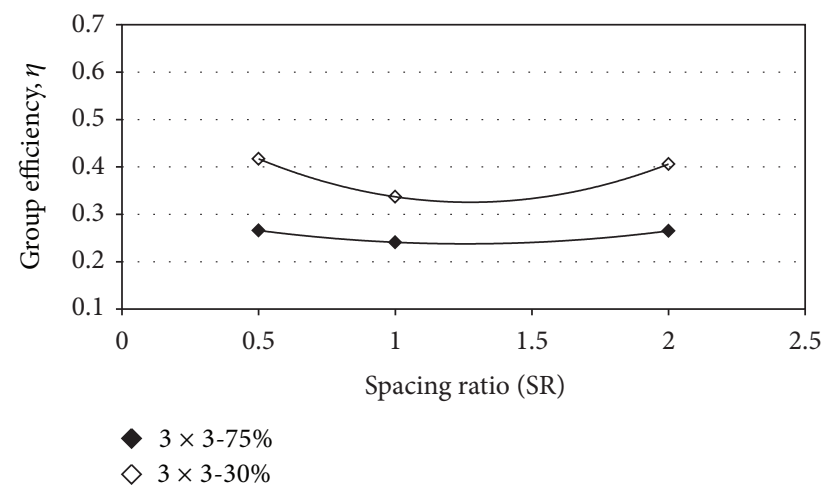

FIGURE 12: Group efficiency versus spacing ratio of piles; (a) $D_{r}=75 \%$ and (b) $D_{r}=30 \%$.

(1) Load-deflection curves were estimated with scaling factors to determine the ultimate lateral resistance of group. The qualitative and quantitative effects of the relative density of the sand have been carried out. The ultimate lateral load was increased $53 \%$ in increasing of $s / d$ from 3 to 6 .

(2) The subgrade modulus decreased with increasing deflection. Width and pile stiffness were two important factors effective on this decreasing.

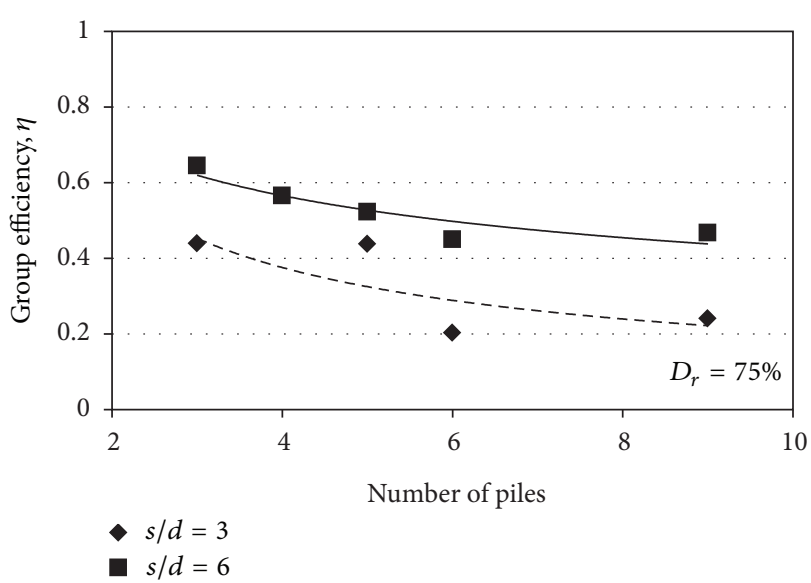

(a)

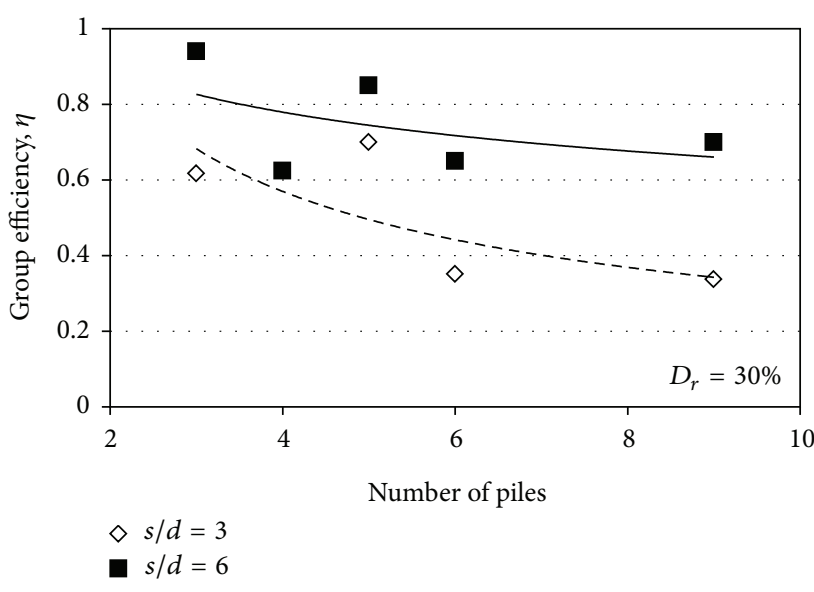

(b)

FIGURE 13: Group efficiency VS number of piles; (a) $D_{r}=75 \%$ and (b) $D_{r}=30 \%$.

(3) Vertical deflection of pile group can be neglected with comparison to horizontal deflection under the lateral loading.

(4) The increase of the number of piles in-group decreased group efficiency owing to the increased overlapping zones and active wedges.

(5) A ratio of $s / d$ more than $6 d$ was large enough to eliminate the pile-to-pile interaction and the group effects. It may be more in the loose sand.

(6) Flexible piles of series arrayed were more resistant than those parallel arrayed to lateral loadings.

\section{Acknowledgments}

The research was undertaken with support from research university Grant (no. Q.J130000.2513.03H63) under the University Teknologi Malaysia (UTM). The first author would like to thank the Ministry of Education (MOE) and the Research Management Center for the financial supports during this study. 


\section{References}

[1] M. Khari, A. K. Kassim, and A. Adnan, "Kinematic bending moment of piles under seismic motions," Asian Journal of Earth Sciences. In press.

[2] M. H. El Naggar, M. A. Shayanfar, M. Kimiaei, and A. A. Aghakouchak, "Simplified BNWF model for nonlinear seismic response analysis of offshore piles with nonlinear input ground motion analysis," Canadian Geotechnical Journal, vol. 42, no. 2, pp. 365-380, 2005.

[3] M. Khari, A. K. Kassim, and A. Adnan, "Dynamic soil-pile interaction under earthquake events," in Proceedings of the AICCE/GIZ'12, Park Royal Penang Resort, Penang, Malaysia, 2012.

[4] M. Khari, A. K. Kassim, and A. Adnan, "Effects of soil model on site response analyses," Asian Journal of Scientific Research. In press.

[5] M. Khari, A. K. Kassim, and A. Adnan, "Development of p-y curves of laterally loaded piles in cohesionless soil," Scientific World Journal. In press.

[6] D. Brown, C. Morrison, and L. Reese, "Lateral load behavior of a pile group in sand," Geotechnical and Geological Engineering, vol. 114, pp. 1261-1276, 1988.

[7] M. Khari, A. K. Kassim, and A. Adnan, "The effects of soil-pile interaction on seismic parameters of superstructure," in Proceedings of the 2nd International Conference on Geotechnique, Construction Materials and Environment (GEOMAT '12), pp. 479-484, Kuala Lumpur, Malaysia, November 2012.

[8] G. G. Meyerhof, A. S. Yalcin, and S. K. Mathur, "Ultimate pile capacity for eccentric inclined load," Journal of Geotechnical Engineering, vol. 109, no. 3, pp. 408-423, 1983.

[9] E. Franke, "Group action between vertical piles under horizontal loads," in Deep Foundations on Bored and Auger Piles, W. F. V. Impe, Ed., Balkema, Rotterdam, The Netherlands, 1988.

[10] N. R. Patra and P. J. Pise, "Ultimate lateral resistance of pile groups in sand," Journal of Geotechnical and Geoenvironmental Engineering, vol. 127, no. 6, pp. 481-487, 2001.

[11] B. T. Kim, N.-K. Kim, W. J. Lee, and Y. S. Kim, "Experimental load-transfer curves of laterally loaded piles in Nak-Dong River sand," Journal of Geotechnical and Geoenvironmental Engineering, vol. 130, no. 4, pp. 416-425, 2004.

[12] J. Zhang, R. D. Andrus, and C. H. Juang, "Normalized shear modulus and material damping ratio relationships," Journal of Geotechnical and Geoenvironmental Engineering, vol. 131, no. 4, pp. 453-464, 2005.

[13] S. Prakash and S. Kumar, "Nonlinear lateral pile deflection prediction in sands," Journal of Geotechnical and Geoenvironmental Engineering, vol. 122, no. 2, pp. 130-138, 1996.

[14] U. Erdal and M. Laman, "Lateral resistance of a short rigid pile in a two-layer cohesionless soil," Acta Geotechnica Slovenia, vol. 2, pp. 19-43, 2011.

[15] S. Narasimha Rao, V. G. S. T. Ramakrishna, and M. Babu Rao, "Influence of rigidity on laterally loaded pile groups in marine clay," Journal of Geotechnical and Geoenvironmental Engineering, vol. 124, no. 6, pp. 542-549, 1998.

[16] M. Khari, A. K. Kassim, and A. Adnan, "Snad sample preparation using mobilepluviator," The Arabian Journal for Science and Engineering. In press.

[17] T. D. Smith, "Pile horizontal soil modulus values," Journal of Geotechnical Engineering, vol. 113, no. 9, pp. 1040-1044, 1987.

[18] B. Broms, "Lateral resistance of piles in cohesive soils," Soil Mechanics and Foundations Division, vol. 90, pp. 27-63, 1964.
[19] A. Wakai, S. Gose, and K. Ugai, “3-D elasto-plastic finite element analyses of pile foundations subjected to lateral loading," Soils and Foundations, vol. 39, no. 1, pp. 97-111, 1999.

[20] B. T. Kim and G. L. Yoon, "Laboratory modeling of laterally loaded pile groups in sand," Civil Engineering, vol. 15, pp. 6575, 2011.

[21] S. R. Gandhi and S. Selvam, "Group effect on driven piles under lateral load," Journal of Geotechnical and Geoenvironmental Engineering, vol. 123, no. 8, pp. 702-709, 1997.

[22] C. S. Oteo, "Displacements of vertical pile group subjected to lateral loads," in Proceedings of the 5th European Conference on Soil Mechanics and Foundation Engineering, pp. 397-405, Madrid, Spain, 1972. 

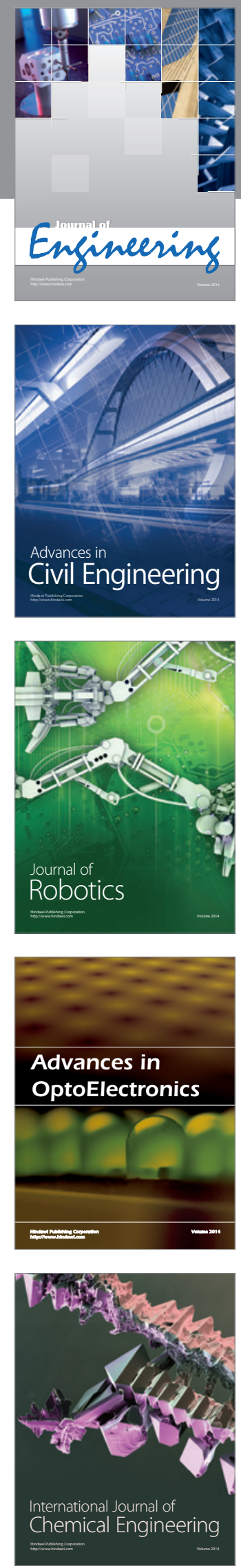

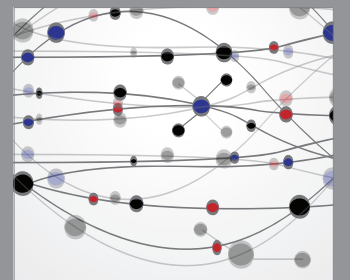

The Scientific World Journal
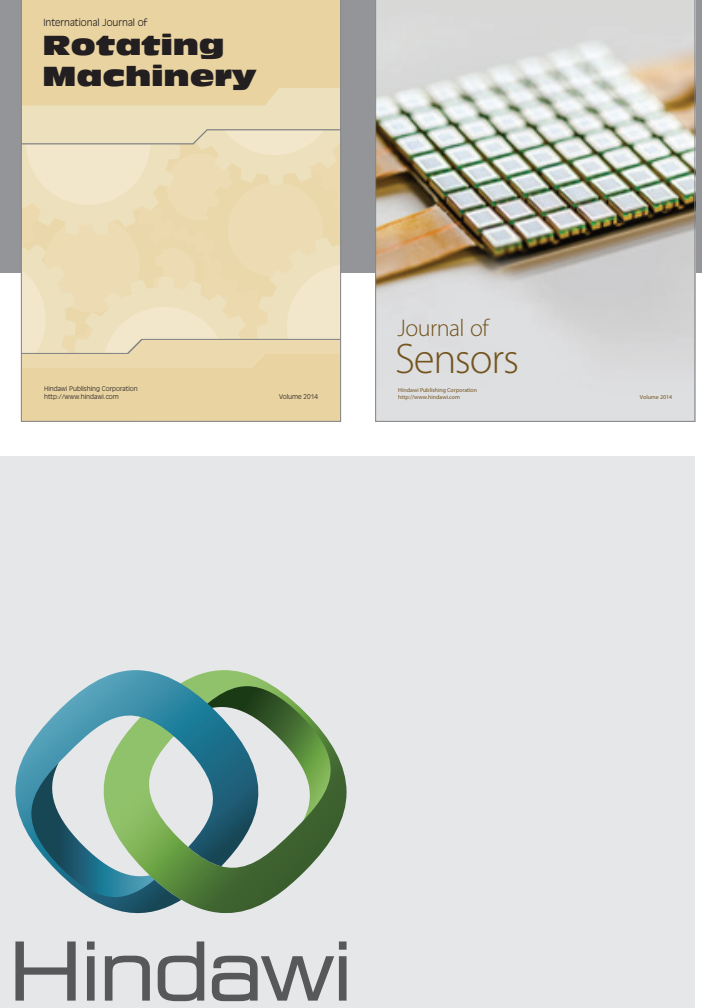

Submit your manuscripts at http://www.hindawi.com
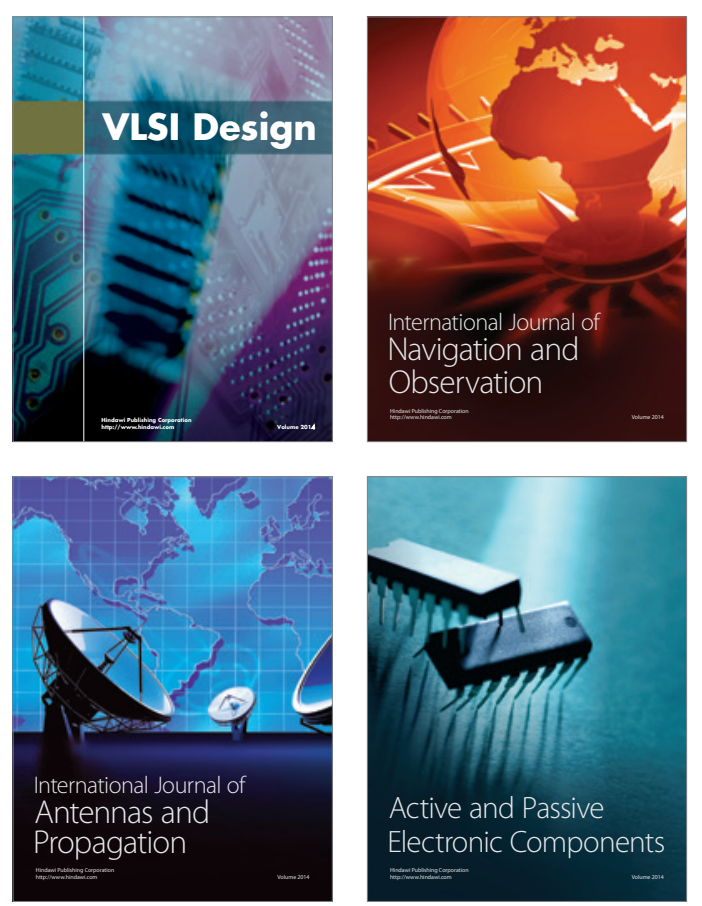
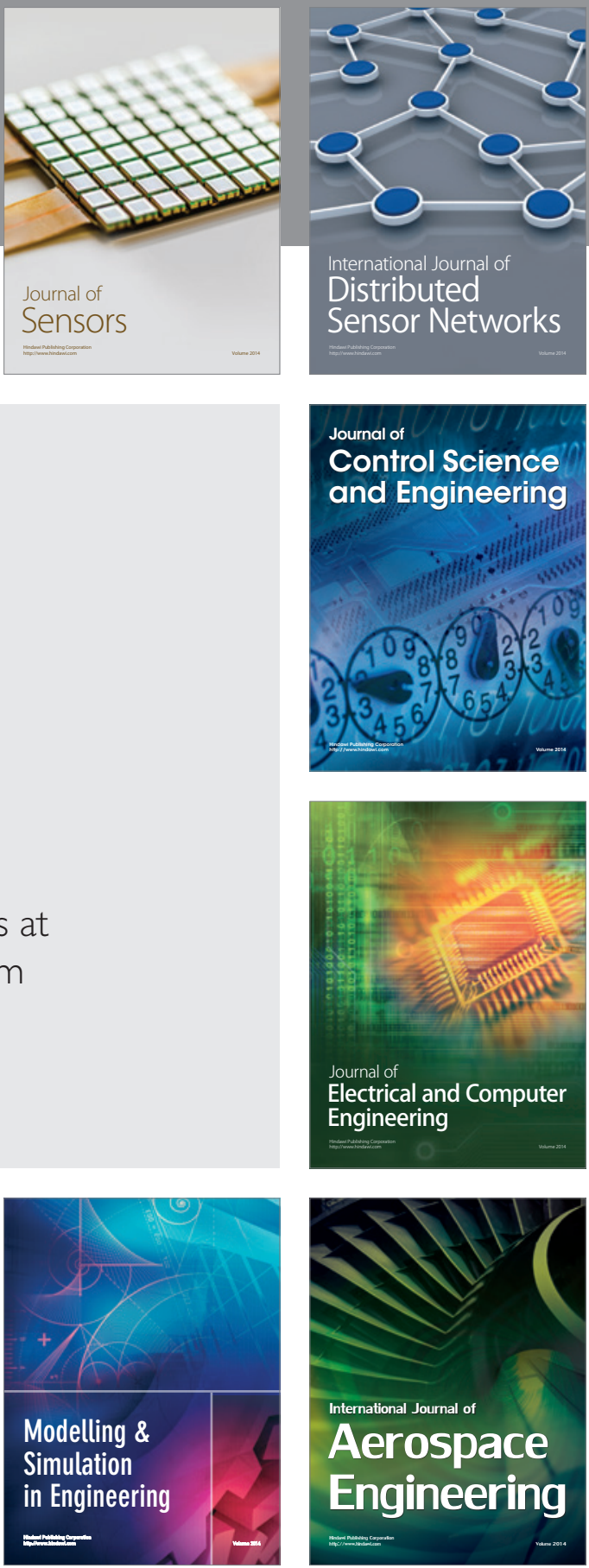

Journal of

Control Science

and Engineering
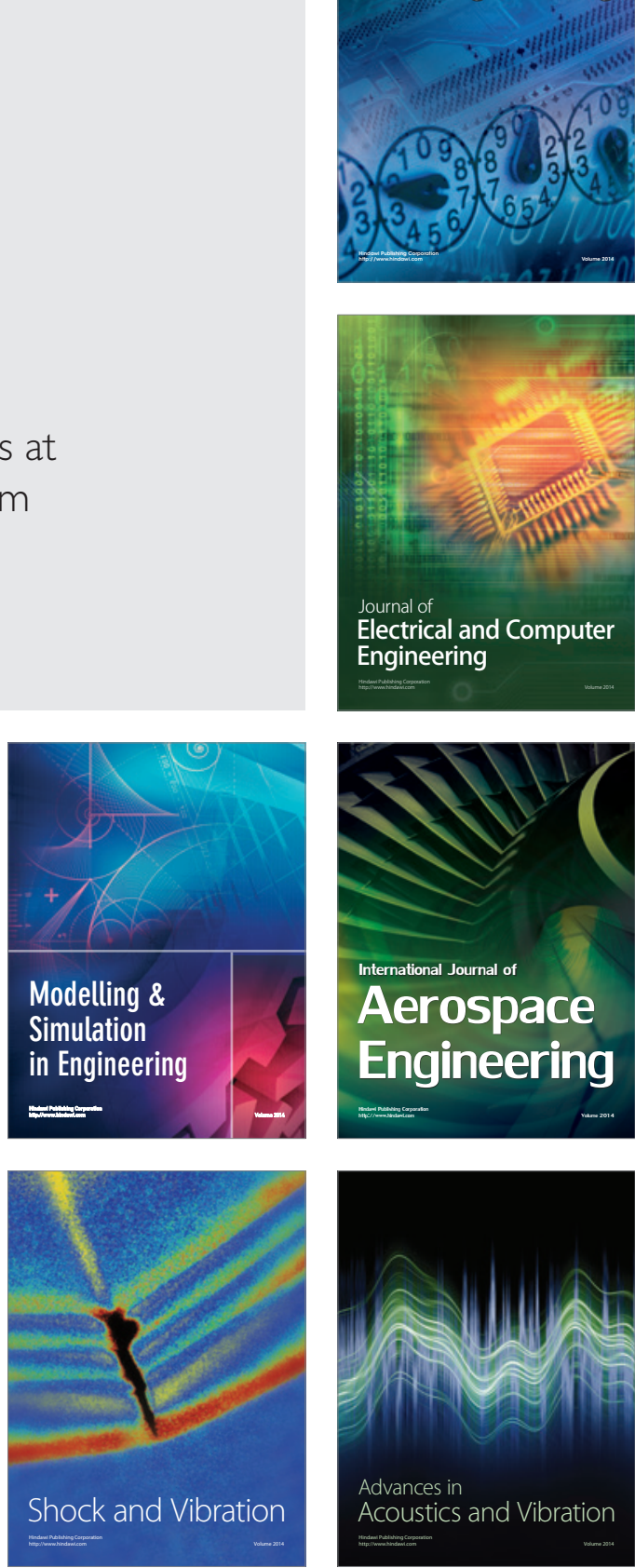